\title{
EXPERIMENTAL INVESTIGATION OF A PORTAL FRAME USING MAGNETORHEOLOGICAL FLUID DAMPER
}

\author{
G. Sailaja* \\ Assistant Professor, Dept. of Mech. Engg., MJCET, Banjara hills, Hyderabad, India \\ N. Seetharamaiah \\ Professor, Dept. of Mech. Engg., MJCET. Banjara hills, Hyderabad, India
}

Maganti Janardhana

Professor, Dept. of Civil Engg, JNTU Hyderabad, India

*Corresponding Author

\begin{abstract}
A Magnetorheological fluid (MRF) damper gives a real solution for semi-active vibration control in vibrations for structures. The performance of the MRF damper depends significantly on the electromagnetic circuit which is integrated into it. The force which is developed by MR fluid damper is greatly influenced by the magnetic flux density induced in the fluid flow gap. In the fields of Civil and Mechanical Engineering, Magnetorheological fluid (MRF) damper based semi-active systems offer protection to structures subjected to mechanical vibrations and also lateral loads due to wind and earthquake forces. In the present work, structural and magnetic analysis of the MR damper is studied and also, the dynamic behavior of a frame when subjected to different forcing frequencies has been discussed.
\end{abstract}

Key words: MR Fluids, SMRF, HMRF, MR Fluid Damper, Structural vibrations.

Cite this Article: G. Sailaja, N. Seetharamaiah, Maganti Janardhana, Experimental Investigation of a Portal Frame Using Magnetorheological Fluid Damper, International Journal of Production Technology and Management (IJPTM), 10(1), 2019, pp. 68-76. http://iaeme.com/Home/issue/IJPTM?Volume=10\&Issue=1

\section{INTRODUCTION}

Magnetorheological Fluid Damper is one of the smart fluid dampers which can be used to suppress the vibrations and to improve the performance. Out of many dampers that are being used, MR fluid damper was found to be more effective than the conventional viscous damper ${ }^{[1]}$. Magnetorheological (MR) fluid was first reported by Rabinow ${ }^{[2]}$ in the year 1948 and he concluded that MR fluids are magnetic field controllable fluids. When the fluid is exposed to 
an external magnetic field, this MR fluid instantaneously changes from a viscous fluid to a semisolid, and forms a chain like structure, depending on the directions of the magnetic field, with a yield strength which is controllable. MR fluids can operate at temperatures ranging from $40{ }^{\circ} \mathrm{C}$ to $150^{\circ} \mathrm{C}$, with only slight variation in Yield stress ${ }^{[3]}$. The main focus of this investigation is to study the performance of the MR Fluid (MRF) dampers on a structure which is vibrated with different speeds. When an electric field is applied to the MR fluid, the fluid becomes a semisolid and behaves as a viscoelastic spring with non-linear vibration characteristics. This transition is reversible and can be achieved in few milliseconds. In the present paper, three types of fluids i.e., MRF (commercially available), HMRF \& SMRF (having 40\% magnetic particles) and HMRF \& SMRF (having 36\% magnetic particles) to use in both single and double stage coil MRF dampers. The test specimen was tested with commercially available Magnetorheological fluid (MRF) and synthesized fluids. These dampers are attached to a frame made up of aluminium and having each bay width of $0.3048 \mathrm{~m}$ and each storey height of $0.3048 \mathrm{~m}$. The frame is subjected to forced vibrations of three different frequencies of $1300 \mathrm{rpm}$, $1350 \mathrm{rpm}$, and $1440 \mathrm{rpm}$. Then the output amplitudes of the frame attached with dampers having different fluids alternately for different current inputs ( 0 to $2 \mathrm{~A})$ are recorded and compared.

\section{MR FLUID AND ITS COMPONENTS:}

MR fluids are suspensions of micron-sized magnetisable particles in a carrier fluid. They mainly consist of the following three components: magnetisable particles, carrier fluid, and some additional additives. These magnetisable particles induce polarization by application of an external magnetic field, which results in the Magnetorheological effect of the MR fluids. This is illustrated in the Fig.1.
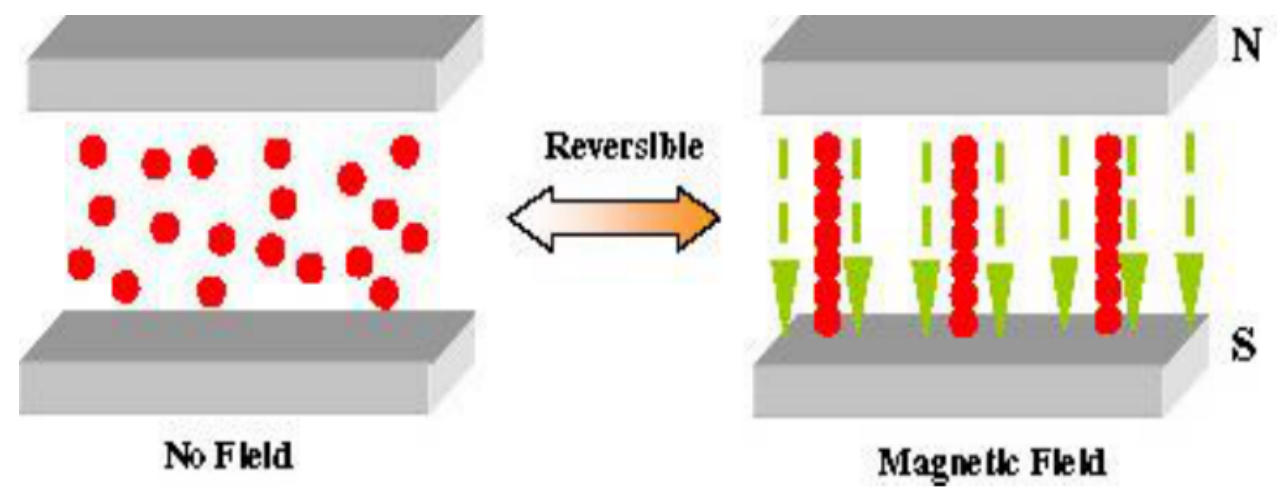

Figure 1 Activation of MR Fluid (Courtesy: www.iopscience.iop.org)

In the absence of an applied magnetic field, the particles in MR fluid disperse randomly in a carrier fluid. MR fluid flows freely through the working gap between the fixed outer cylinder and rotor. The dynamic behavior of MR fluids has been developed through annular duct using Navier-Stokes equation based on the Herschel-Bulkley and Bingham models for nonNewtonian fluid flows ${ }^{[4]}$.

The composition of MR fluid includes a carrier fluid, magnetic-responsive particles, and hydrophobic organ clay. The hydrophobic organ clay is present as an anti-settling agent, which provides soft sediment once the magnetic particles settle out. The compositions form a thixotropic network that is effective at minimizing particles settling and also in lowering the shear forces required to re-suspend the particles once they settle. The composition described herein have a relatively low viscosity, do not settle easily, and can be easier to re-disperse than conventional Magnetorheological fluids, including those which contain conventional anti settling agents such as silicon dioxide or silica. The composition typically has atleast $10 \%$ less 
sediment hardness than comparative fluids that include silica rather than the hydrophobic organ clay, where the test involves repeated heating and cooling circles over a two weeks period. The compositions may cause $10 \%$ less device wear than comparative fluids that include silica rather than the hydrophobic organ clay ${ }^{[5]}$. Any solid that is known to exhibit magnetorheological activity can be used as a suspension within the carrier fluid. Examples of suitable magnetizable particles include iron, iron alloys (such as those including aluminum, silicon, cobalt, nickel, vanadium, molybdenum, chromium, tungsten, manganese and/or copper), iron oxides (including $\mathrm{Fe}_{2} \mathrm{O}_{3}$ and $\mathrm{Fe}_{3} \mathrm{O}_{4}$ ), iron nitride, iron carbide, carbonyl iron, nickel, cobalt, chromium dioxide, stainless steel and silicon steel. A preferred magnetic responsive particulate is carbonyl iron, preferably, reduced carbonyl iron.

\section{MRF DAMPER AND ITS OPERATIONAL PRINCIPLE}

Magnetorheological damper is a device to give damping by the shear stress of the fluid. The property of damper is that the damping changes quickly in response to an external magnetic field strength when applied. Fig.2and Fig.3 shows sectional view and various components of the MR damper.

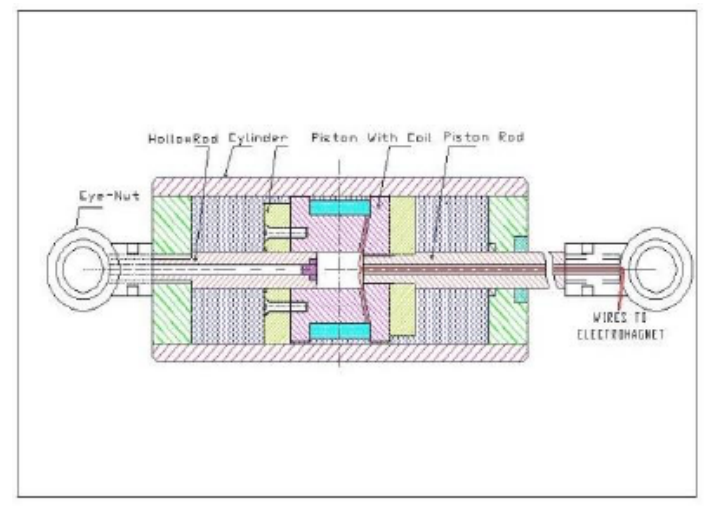

Figure 2 Internal details of MRF Damper

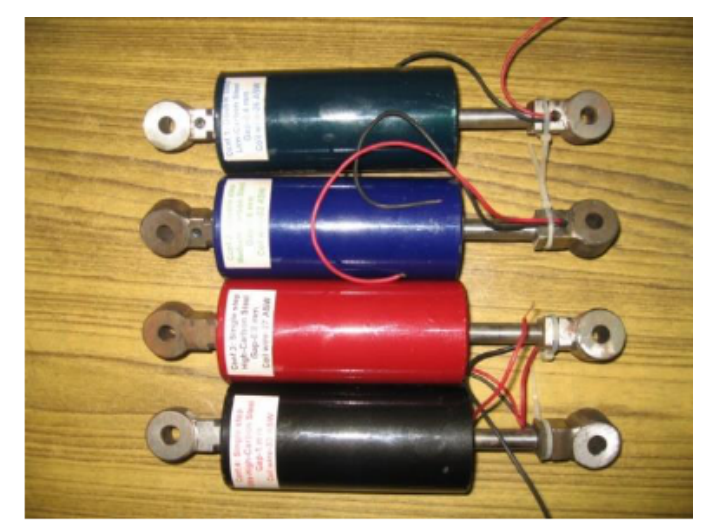

Figure 3 MR Dampers (single coil and double coil)

The MR fluid is filled in the working gap between the fixed outer cylinder and inner cylinder. In the absence of an applied magnetic field, the suspended particles of the MR fluid cannot restrict the relative motion between the fixed outer and inner cylinder, but in the course of operation a magnetic flux path is formed when the electric current passes through the magnetic coil. As a result, the particles are gathered to form the chain-like structures, with the direction of the magnetic flux path. These chains like structures restrict the motion of the MR fluid, thereby increasing the shear stress of the fluid. The damping can be achieved by utilizing the shear force of MR fluid. The damping values can be adjusted continuously by changing the external magnetic field strength.

\section{STRUCTURAL ANALYSIS OF MR FLUID DAMPER:}

The structural analysis of MR dampers is carried out. The pressure values are calculated and the cylinder of the damper is analyzed for the maximum pressure value using ANSYS. The effect of maximum pressure on other parts is also discussed. The meshing of the damper model is done using Hyper Mesh software. The meshed assembly of the damper is shown in the Fig. 4. The element type used for meshing is SOLID45. The overall number of nodes taken here is 35334 while the overall elements number comes out to be 144975 . The meshed 3D model of the damper is shown in the fig. The structural Analysis of MR damper is important for predicting the behaviour of the damper under various load conditions as well as internal pressure changes. For this model, Pressure Analysis is done for the maximum pressure of 4 
MPA which is applied on internal surface of the cylinder and all Degrees of Freedom constraints are given on the eyenuts.

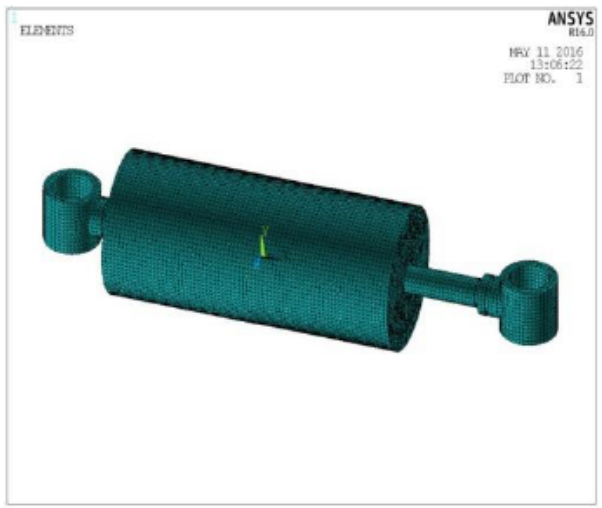

Figure 4 Meshed assembly of MR damper

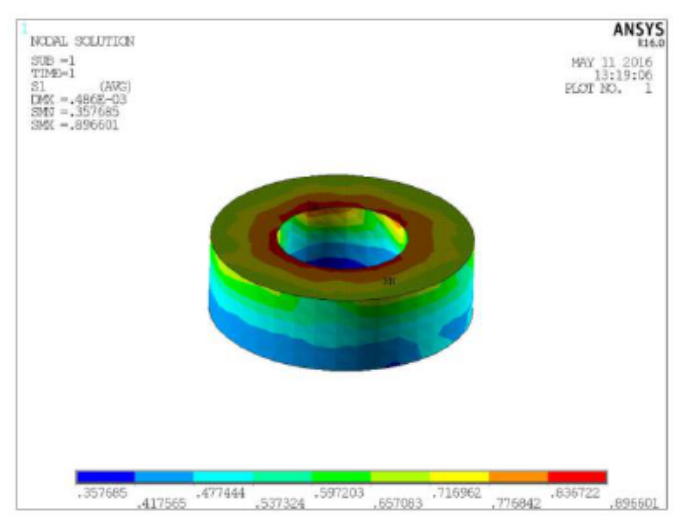

Figure 6 Principle stress in piston ring.

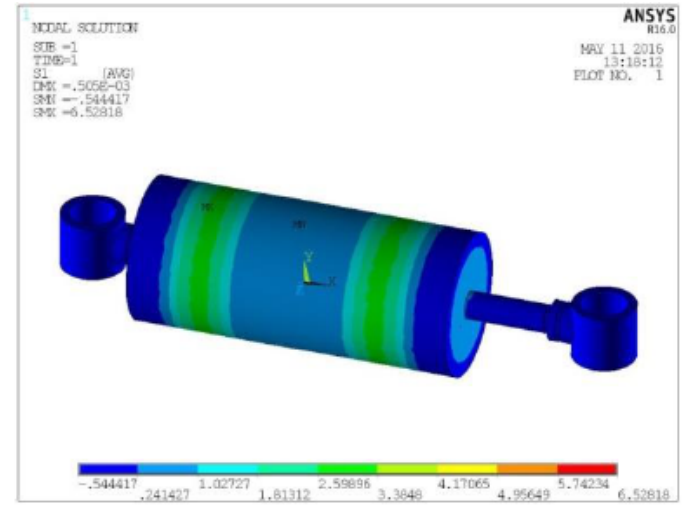

Figure 5 principle stress in damper

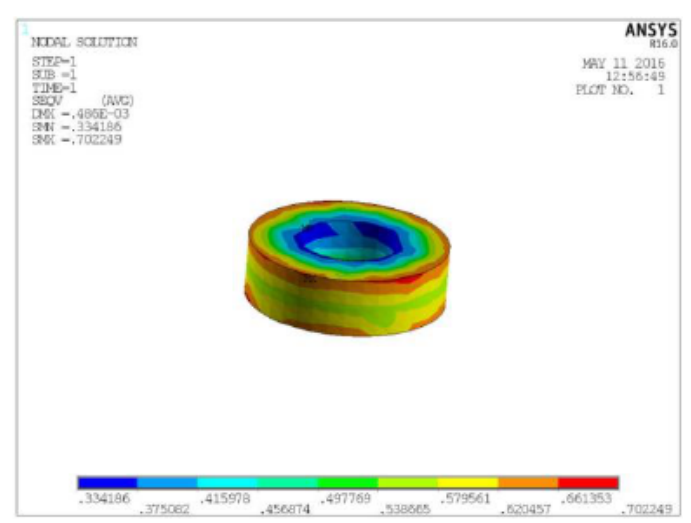

Figure 7 Von-mises stress in piston ring

The above figures i.e., Figs. 5 to 7, gives the principle stresses and von-mises stresses of the damper. It is clear from the results that the stresses developed in the damper are well within the limit of the material. Here the material of the damper is low carbon steel. Hence it can be concluded that the dimensions and various parameters calculated for the development of the damper are safe and the MR damper can be used for mitigation of structural vibrations.

\section{MAGNETIC ANALYSIS OF MR FLUID DAMPER}

The magnetic analysis of the damper is done to verify the magnetic field strength of the coil, for the designed air gap of $0.4 \mathrm{~mm}$ and for both double stage coil and single stage coil and optimal results were obtained.

In the Fig.8, the magnetic flux density in the cylinder is shown. From the colour code it can be seen that the magnetic flux in the cylinder is minimum which is due to the material of cylinder. The magnetic flux density in the gap (fluid) is shown in Fig. 10. From the colour code it can be seen that the maximum strength of the field is in the region between the cylinder and piston (red colour). This result is desired as per design of the damper. The maximum magnetic flux density value in the fluid gap region is $2.601 \mathrm{~T}$ and this is due to the minimum fluid gap of $0.4 \mathrm{~mm}$. The magnetic flux density in piston is shown in Fig. 9. From the colour code it can be seen that the field strength is average in piston. This is due to the material of the piston i.e. copper which is desired as per the dampers design. The magnetic analysis for the damper is conducted. In the Fig.11, the magnetic flux density in the cylinder is shown. From the colour code it can be seen that the magnetic flux in the cylinder is minimum which is due to the material of cylinder. 


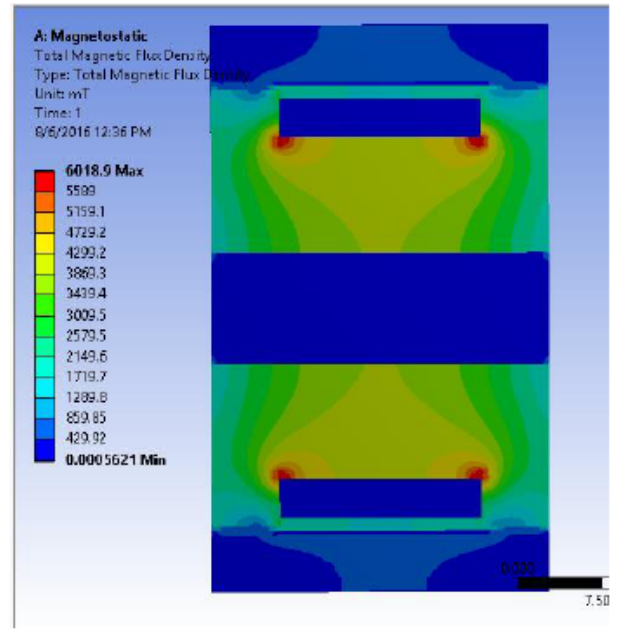

Figure 9 Magnetic Flux Density in Piston

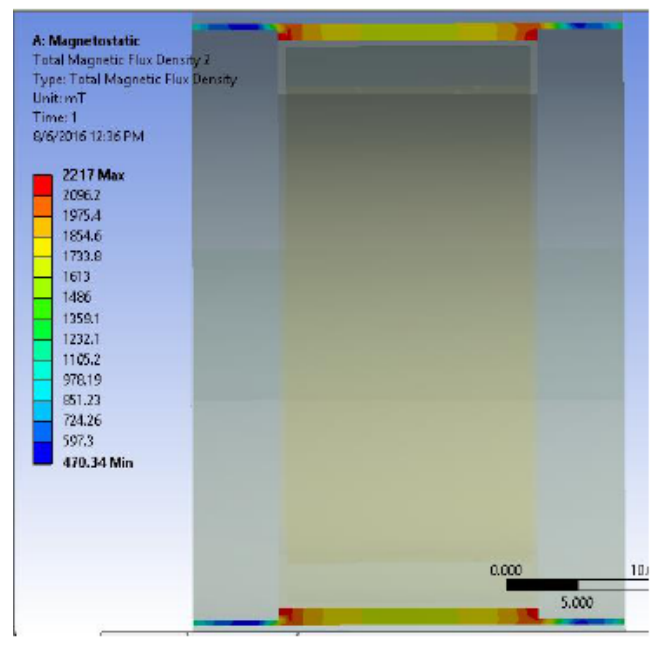

Figure 10 Magnetic Flux Density in gap (Fluid)

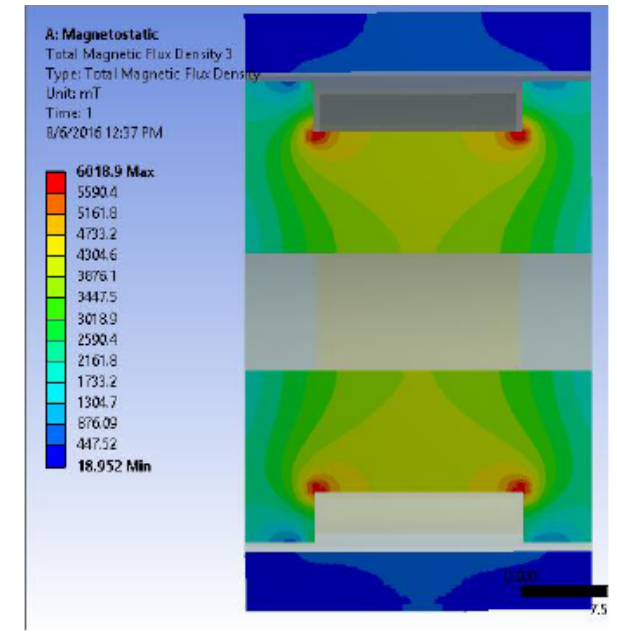

Figure 8 Magnetic Flux Density in Cylinder

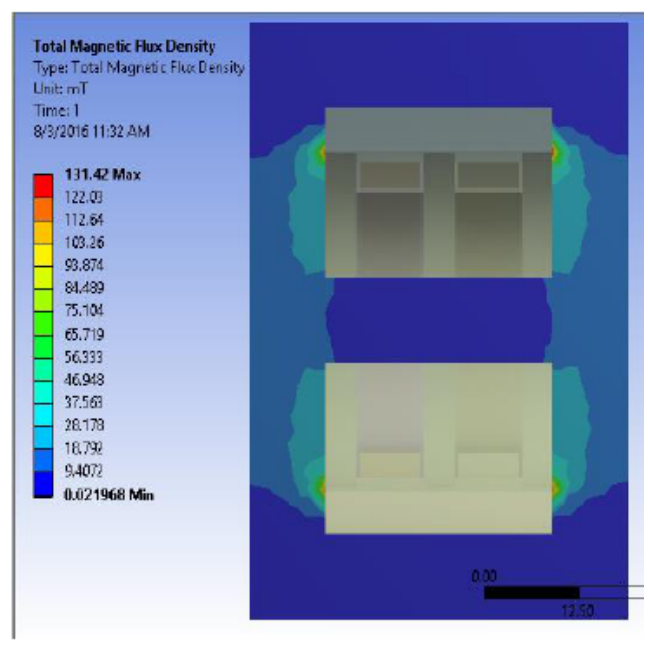

Figure 11 Magnetic Flux Density in Cylinder

\section{EXPERIMENTAL INVESTIGATION OF STRUCTURAL VIBRATIONS}

The experimental setup used in the study of structural vibrations using MR dampers consist of a structure (single bay four storeyed portal frame), vibrator, MR dampers, accelerometer (pick up), signal conditioner, digital storage oscilloscope (DSO), power source system.

To investigate the behaviour of the MR dampers and the structure, a series of experiments were conducted. The experimental investigations for frequency analysis on structural frame with MR dampers which were filled with MRF-132DG (commercially available) MRF40 and MRF36 with different carrier fluids (silicon oil and hydrocarbon oil) termed as SMRF40, SMRF36, HMRF40 and HMRF36 simultaneously were performed by varying input current to the dampers. The experimental results with two different dampers i.e. single stage coil and double stage coil are compared. 


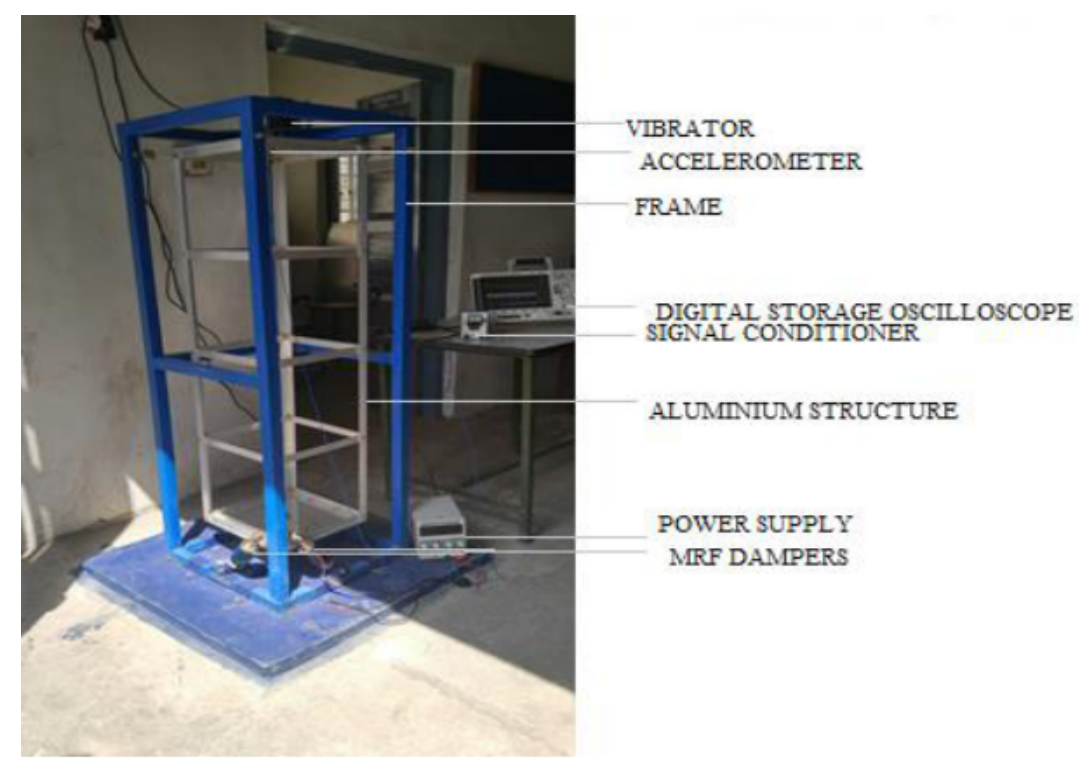

Figure 12 Experimental set-up

In the experiment, speed of the motor i.e. vibrator is of $1300 \mathrm{rpm}, 1350 \mathrm{rpm}, 1440 \mathrm{rpm}$ were utilized. The input currents sent to the damper's coil were constant at $0,0.5,1,1.5$ and $2 \mathrm{~A}$ respectively. The single stage and double stage MR dampers are filled with MR fluid MRF132DG (commercially available), HMRF40, HMRF36 (carrier fluid- hydrocarbon oil), SMRF40 and SMRF36 (carrier fluid- silicon oil) were tested using the experimental setup. The aforementioned characteristics (different motor speeds and variable input current effect) were tested and the results were plotted.

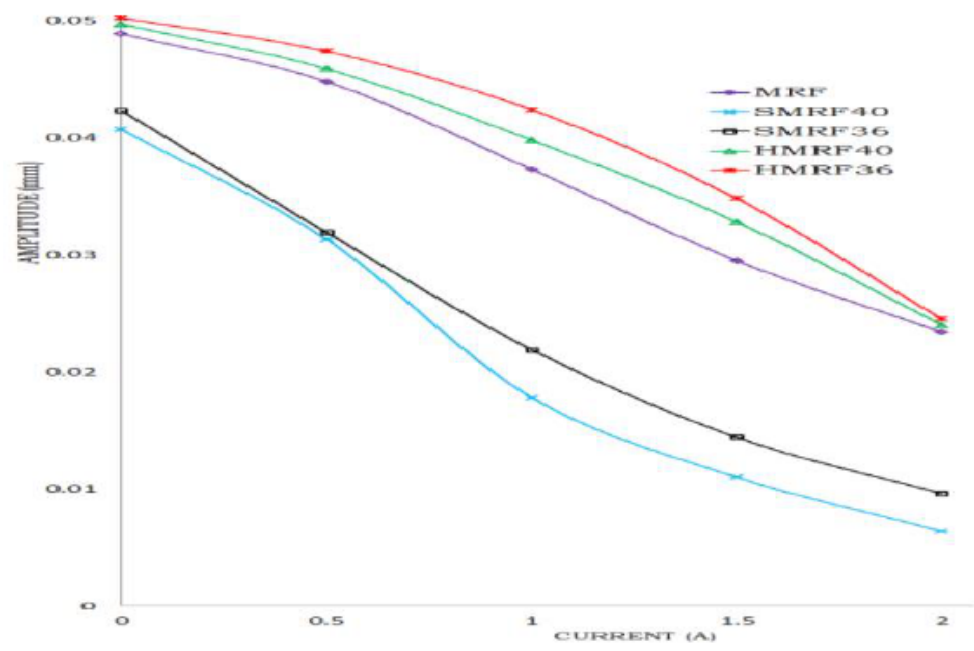

Figure 13 Response of the portal frame with single stage coil damper at $1300 \mathrm{rpm}$. 
G. Sailaja, N. Seetharamaiah, Maganti Janardhana

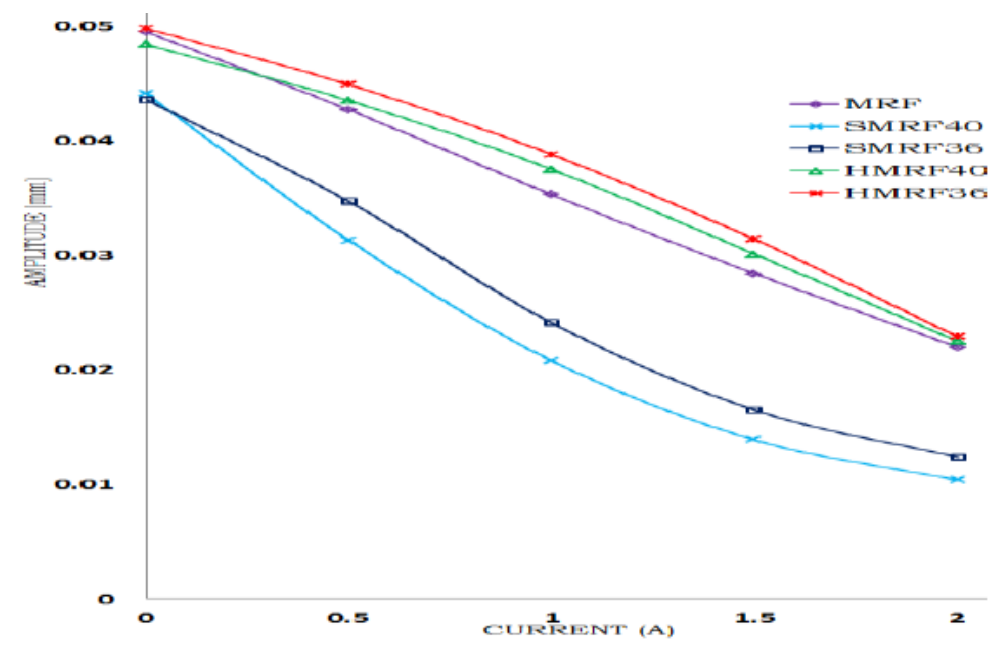

Figure 14 Response of the portal frame with single stage coil damper at $1350 \mathrm{rpm}$

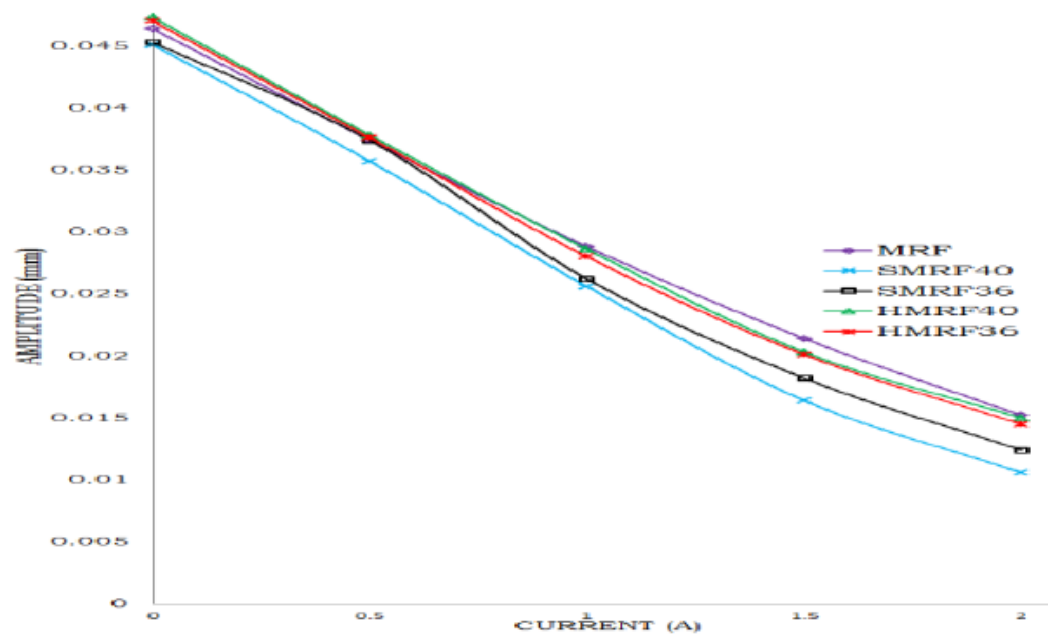

Figure 15 Response of the portal frame with single stage coil damper at $1440 \mathrm{rpm}$.

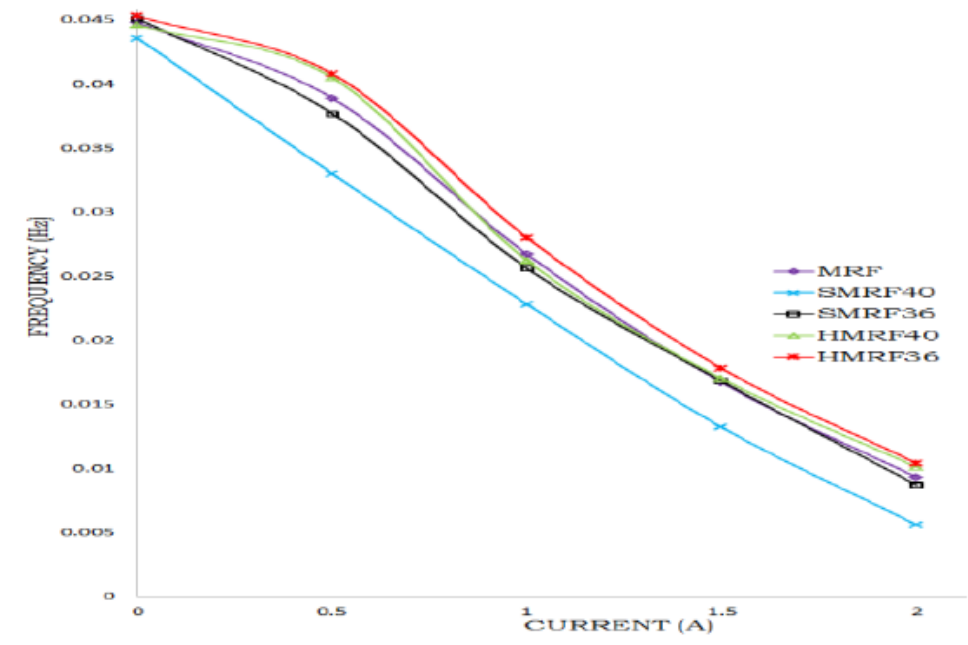

Figure 16 Response of the portal frame with double stage coil damper at $1300 \mathrm{rpm}$. 


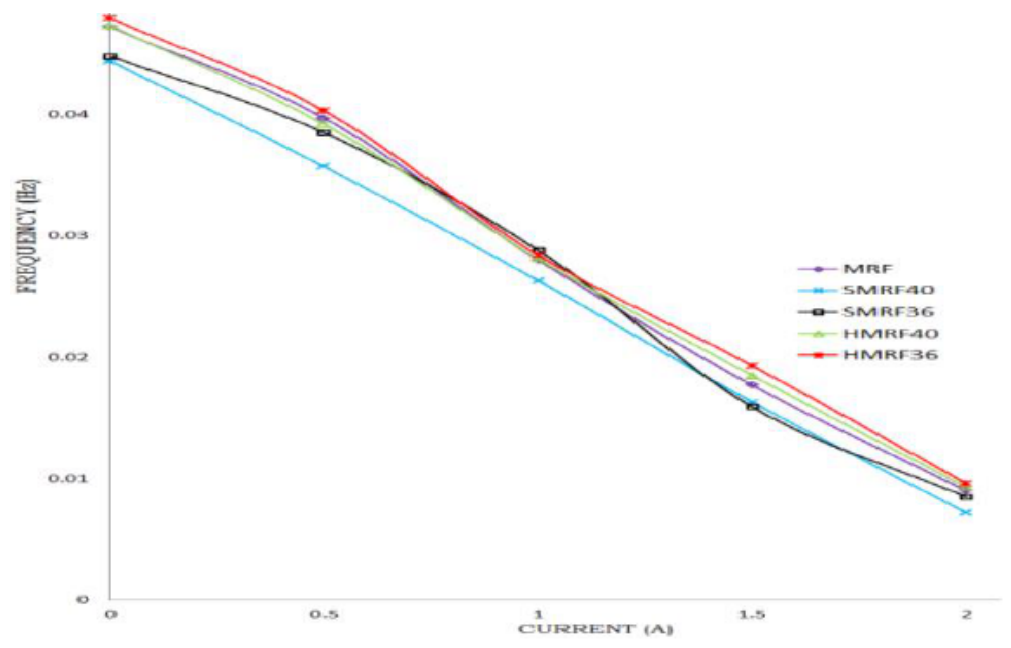

Figure 17 Response of the portal frame with double stage coil damper at $1350 \mathrm{rpm}$.

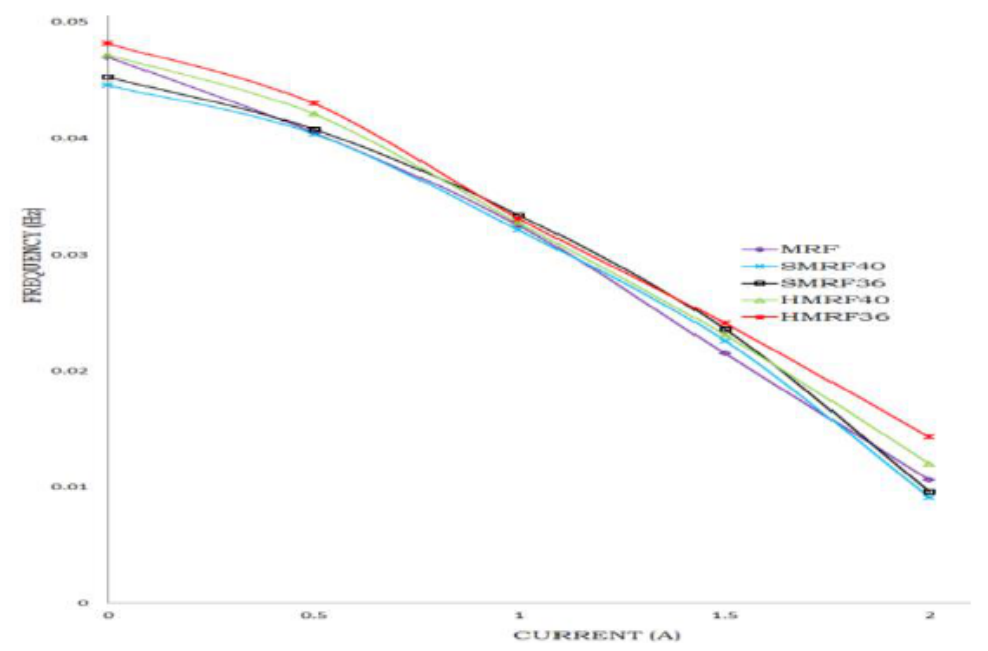

Figure 18 Response of the portal frame with double stage coil damper at $1440 \mathrm{rpm}$.

\section{RESULTS AND DISCUSSIONS}

Fig. 13 shows the dynamic response of the portal frame with single stage coil damper at a forcing frequency of $1300 \mathrm{rpm}$. When the input current is less than $0.5 \mathrm{~A}$, the two curves of silicon based MRFs are crossing each other and further the amplitude of SMRF40 is getting reduced more when compared to the amplitude of SMRF36. Also, it is seen that, when compared to the commercially available MRF, the amplitudes of synthesized silicon based MR fluids (SMRF40, SMRF36), are decreasing to a greater extent. But, the hydrocarbon based MR fluids (HMRF40, HMRF 36) are nearly decreasing as that of commercially available MR fluid. At a speed of $1350 \mathrm{rpm}$, it has been observed that the deviation between hydro-carbon based MRFs and silicon based MRFs is less when compared with that of the speed of $1300 \mathrm{rpm}$ as shown in the Fig. 14. When the forcing frequency is increased to $1440 \mathrm{rpm}$, as shown in Fig. 15 , the plots of all the fluids are seen as a cluster and all are showing the same performance. It is evident from the Figs. 13, 14 and 15 that, as the speed goes on increasing the performance of all the fluids are becoming nearly same.

Figs 16, 17 and 18 show the response of the portal frame with double stage coil damper at a forcing frequency of $1300 \mathrm{rpm}, 1350 \mathrm{rpm}$ and $1440 \mathrm{rpm}$ respectively. From the Fig. 16, amplitude of the vibrating structure is reduced, but it is observed that the curves are parabolically downwards up to $1 \mathrm{~A}$ of current and then it started going upwards. But the curve of SMRF40 is going parabolically upwards. As the speed increases the SMRF40 curve changes 
its direction from inward parabola to the outward parabola. It is evident that the variation of amplitude of SMRF40 is low at lower currents and high at higher currents. It is also evident, from the Fig. 18, that the deviation of the curves seems to be also parabolic but projecting towards down. It is observed that at $1440 \mathrm{rpm}$ all the five fluids are reducing the vibrations almost in the same range. Hence, it is clearly observed that the variation of amplitude is nonlinear and non-uniform. It purely depends upon the type of MR Fluid, type of damper and forcing frequency.

\section{REFERENCES}

[1] Butzt, VonStryk O. Modelling and Simulation of Rheological Fluid devices, Preprint SFB438-991, Sonderforschunsbereich 438 TechicheunversitatMunchan, 1999.

[2] Rabinow J. Magnetic fluid clutch National Bureau of standards Technical News Bulletin 32(4): 54-60(1948)

[3] Carlson JD, Sproston JL. Controllable fluids in 2000- status of ER and MR fluid Technology. In $7^{\text {th }}$ international conference on New Actuator,Bermen, 2006: 126-130 .

[4] Sailaja, G., Seetharamaiah, N. and Janardhana, M. Modeling the Dynamic behavior of MR Fluid Damper for Structural Vibration Mitigation, International Conference On Advanced Materials And Manufacturing Technologies, Dec 18-20 2014 pp.304-311.

[5] Sailaja, G., Seetharamaiah, N. and Janardhana, M. Design and finite element analysis of MR fluid damper for structural vibration mitigation, International Journal of Mechanical Engineering and Technology (IJMET) Volume 7, Issue 4, July-Aug 2016, pp.143-151, Article ID: IJMET_07_04_014.

[6] Mark R. Jolly, Jonathan W. Bender and J. David Carlson, Properties and Applications of Commercial Magnetorheological Fluids, Personal Communication.

[7] Liwei, Lizhongxian and Ding Yang, Trust region based instantaneous optimal semi-active control of long span spatially extended structures with MRF-04 k dampers.

[8] S. Timoshenko, 1928, Vibration Problems in Engineering, $1^{\text {st }}$ Edition, Van Nostrad, New York.

[9] J. P. Den-Hartog, 1934, Mechanical Vibrations, $1^{\text {st }}$ Edition, McGraw-Hill, New York.

[10] Neil David Sims, 1999, Modelling and Control of an Electrorheological Long-Stroke Vibration Damper, Ph.D.Thesis, Department of Mechanical Engineering, The University of Sheffield, UK.

[11] Guangqiang Yang, 2001, Large-scale Magnetorheological Fluid Damper for Vibration Mitigation: Modeling, Testing and Control, Ph.D. Thesis, Department of Civil Engineering and Geological Sciences, University of Notre Dame, Indiana, USA. 